\title{
IMPACTO AMBIENTAL EM UNIDADES DE CONSERVAÇÃO OCASIONADO POR ESPÉCIES EXÓTICAS
}

\author{
José Edimar Vieira Costa Júnior ${ }^{1}$
}

Cláudia de Oliveira Gonçalves Nogueira²

\section{Luís Antônio Borges Coimbra ${ }^{3}$}

Resumo: Espécies exóticas são aquelas espécies que se encontram fora de sua área de distribuição natural, ameaçando ecossistemas, habitats ou espécies, devido suas vantagens competitivas e favorecidas pela ausência de predadores e pela degradação dos ambientes naturais. Causando enormes prejuízos à economia, à biodiversidade e aos ecossistemas naturais, além dos riscos à saúde humana. A contaminação biológica por espécies se intensificou em tempos pré-industriais, quando as pessoas transportavam e cultivavam, longe dos locais de origem, plantas ornamentais, florestais e agrícolas. Esse processo cresceu com a globalização, com a ampliação das vias de transporte, mudanças no uso da terra e climáticas, propiciando a introdução e expansão das espécies exóticas invasoras. As Unidades de Conservação estão protegidas sob a Lei 9.985 de julho de 2000, onde em seu art. 31 torna-se proibida à introdução de espécies que não seja autóctone. Porém, o manejo efetivo de Unidades de Conservação precisa incluir um sistema permanente de prevenção e detecção precoce de espécies exóticas, assim como um bom diagnóstico de espécies já existente.

Palavras-chave: Espécies Exóticas. Unidades de Conservação. Impacto Ambiental. 


\section{INTRODUÇÃO}

Entende-se como espécies exóticas invasoras aquelas espécies que se encontra fora de sua área de distribuição natural, ameaçando ecossistemas, habitats ou espécies, devido suas vantagens competitivas e favorecidas pela ausência de predadores e pela degradação dos ambientes naturais, dominando os nichos ocupados pelas espécies nativas, notadamente em ambientes frágeis e degradados (MMA, 2013).

Segundo Ziller 2001, o processo de invasão de um ecossistema por uma espécie exótica - a contaminação biológica - se dá quando qualquer espécie não natural de um ecossistema é introduzida nele e se naturaliza, passando a se dispersar e a alterá-lo.

Espécies exóticas invasoras são reconhecidas, atualmente, como uma das maiores ameaças biológicas ao meio ambiente, com enormes prejuízos à economia, à biodiversidade e aos ecossistemas naturais, além dos riscos à saúde humana, sendo também considerada a segunda maior causa de perda de biodiversidade, após as alterações de habitats (MMA, 2013).

Para definir se uma espécie é nativa ou não de uma região, Dechoun 2012, alerta que não podem ser utilizados os limites geográficos por nós estabelecidos, como divisas de municípios, estados ou países. Deve-se segundo o mesmo autor utilizar as regiões biogeográficas de domínio dos diferentes biomas e ecossistemas, e as diferenças determinadas pelo clima em diferentes regiões para determinar as distribuições das espécies. Com base nisso, uma espécie da região Amazônica, por exemplo, em um estado da região Sul do país, localizado no Bioma Mata Atlântica, deve ser chamada de espécie exótica, e pode ser chamada de invasora, caso possa provocar impactos ambientais.

A introdução de plantas e animais além de sua área de distribuição natural tem sido cada vez maior como resultado de oportunidades de transporte, comércio, viagens e turismo entre diferentes países e continentes (DUCHOUN, 2010).

Em parques nacionais, bem como em outras categorias de áreas protegidas, os impactos negativos podem ser gerados por diferentes atividades inadequadas como de uso público, gerando impactos biofísicos, que interferem sobre a qualidade do solo, a água, vegetação e fauna (ANDRADE et al., 2012), e, sociais, quando relacionados à perda de qualidade na experiência do visitante (LEUNG; MARIOM, 2000). 
Para Pickering; Hill (2007), as atividades de recreação provocam efeitos diretos, como o pisoteio sobre a vegetação e o aumento da erosão, e, indiretos, como a introdução e a dispersão de espécies exóticas e de patógenos.

Sabe-se que, atualmente, grande parte das Unidades de Conservação no Brasil contém espécies exóticas invasoras, destacando que não há registro específico de Unidades de Conservação que não possuam espécies exóticas invasoras em seu interior, ainda que isso seja possível, especialmente no bioma Amazônia (LEÃO et al., 2011).

Ainda o mesmo autor, a presença de espécies exóticas invasoras nessas áreas é incompatível com a conservação da biodiversidade e dos recursos naturais e devem ser objeto de erradicação ou de controle permanente.

O presente trabalho teve como objetivo realizar uma análise sobre impacto ambiental ocasionado pela introdução de espécies exóticas invasoras em Unidades de Conservação.

\section{A INTRODUÇÃO DE ESPÉCIES EXÓTICAS}

Ao longo dos anos, as atividades agrícolas, florestais e ornamentais levaram a humanidade a transportar e cultivar, longe de seus locais de origem, diversas plantas com o objetivo de suprir suas necessidades, trazendo para o homem um grave problema, que é o que definimos como contaminação biológica ou invasão biológica por espécies (GOMES, 2007).

De acordo com as definições adotadas pela Convenção Internacional sobre Diversidade Biológica (CDB, 1992) na 6ª Conferência das Partes (CDB COP-6, Decisão VI/23, 2002), uma espécie é considerada exótica (ou introduzida) quando situada em um local diferente do de sua distribuição natural por causa de introdução mediada por ações humanas, de forma voluntária ou involuntária

Para Ziller et al., (2004) espécies exóticas são aquelas que, uma vez introduzidas, a partir de outros indivíduos, se adaptam e passam a reproduzir-se a ponto de ocupar o espaço de espécies nativas e produzir alterações nos processos ecológicos naturais, tendendo a tornar-se dominantes após período de tempo mais ou menos longo, requerido para a sua adaptação. 
Em tempos pré-industriais, as pessoas rompiam as barreiras geográficas transportando muitas espécies as quais eram limitadas por fatores climáticos e ambientais à sua dispersão, como exemplos dessa barreiras temos os oceanos, rios e montanhas (GOMES, 2007).

As primeiras translocações de espécies de uma região a outra do planeta foram intencionais e buscavam, basicamente, suprir necessidades agrícolas, florestais e outras de uso direto (LEÃO et al., 2011). A crescente globalização, a ampliação das vias de transporte, o incremento do comércio e do turismo internacional, aliado às mudanças no uso da terra, das águas e às mudanças climáticas decorrentes do efeito estufa, tendem a ampliar significativamente as oportunidades e os processos de introdução e de expansão de espécies exóticas invasoras nos diversos ecossistemas da terra (MMA, 2009).

Nos últimos tempos, os objetivos de translocações de espécies mudou, aumentando cada vez mais a proporção de introduções de espécies ornamentais, passando a se espalhar, tornando-se prejudicial a manutenção da biodiversidade da Terra e bem-estar das populações humanas (BINGGELI, 2000).

No caso de espécies de insetos e outros invertebrados terrestres, assim como para organismos marinhos, a tendência se inverte, e a maioria das espécies é introduzida acidentalmente, em água de lastro ou por embarcações que cruzam limites naturais que haviam permanecido constantes durante milhões de anos de evolução (ZILLER; ZALBA, 2007).

De acordo com Ziller; Zalba 2007, um dos maiores desafios no trabalho com espécies exóticas invasoras está na dificuldade de fazer as pessoas compreenderem que a invasão é um processo dinâmico e crescente, não um fato estável (FIGURA 1). Quando uma espécie supera as barreiras geográficas que a limitam à sua área de distribuição natural e é introduzida em novo ambiente, três situações podem se desenvolver: que não 
sobreviva, que se estabeleça e persista apenas localmente, ou que se torne invasora.

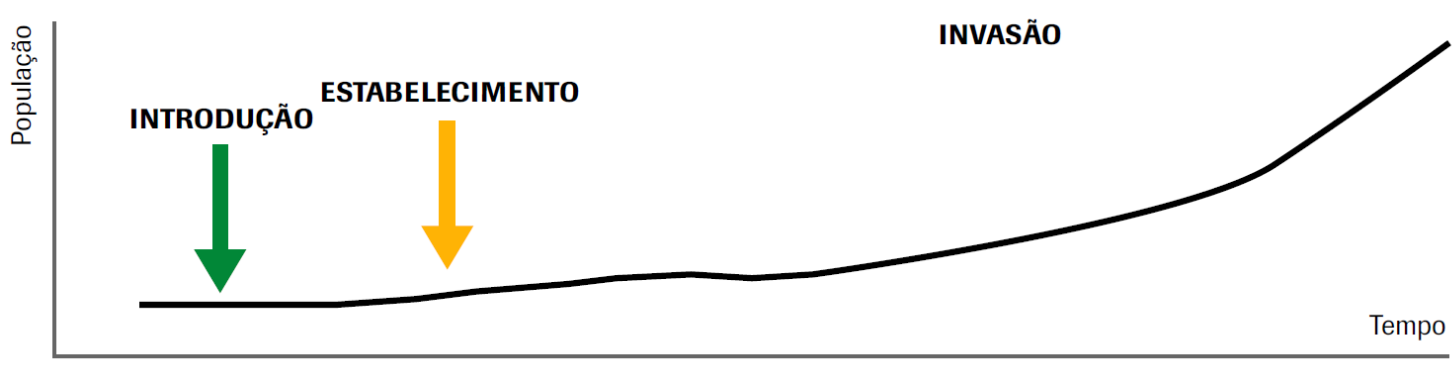

Figura 1: O processo de invasão biológica

Uma vez introduzida, a espécie precisa ultrapassar barreiras ambientais para sobreviver, que vão desde condições climáticas e de solos até o ataque de predadores e patógenos. Superadas essas barreiras, considera-se uma espécie como estabelecida quando passa a formar populações auto-regenerativas, ou seja, a reproduzir-se localmente. Esse é o segundo passo no processo de invasão. A terceira barreira que a espécie precisa ultrapassar para se tornar invasora refere-se à capacidade de dispersão além do ponto onde foi introduzida. Uma vez que a espécie encontre meios de se propagar para áreas mais amplas, seja por meios físicos como o vento, por associação com outras espécies que funcionem como dispersores, por ajuda indireta do homem (por exemplo, no caso de espécies que se propagam seguindo canais de irrigação ou as margens de estradas e caminhos) ou por meios próprios, como é o caso dos animais, passa a ser considerada invasora.

Segundo Mack et al., 2000, o intervalo do momento entre a introdução da espécie e o tempo em que ela adquira capacidade à dispersão tornando-se invasora é denominado de latência.

Ziller; Zalba 2007 enfatiza que:

Esse tempo é imprevisível, pois varia para cada espécie em cada situação ambiental e depende de fatores como o tempo de amadurecimento até a reprodução sexual, o tempo necessário para que produza grandes quantidades de sementes ou descendentes, o número de anos entre ciclos climáticos favoráveis para seu estabelecimento, ou uma combinação desses e de outros fatores. A fase de latência depende também da pressão de propágulos, medida pelo esforço de introdução, seja pelo número de indivíduos da espécie introduzidos ou pelo número de repetições da introdução. Ambos os fatores aumentam as chances de estabelecimento. 
Como consequências da invasão de espécies exóticas ocorrem custos ambientais, econômicos e à saúde humana.

\section{- Custos Ambientais}

Em ecossistemas pobres de nutrientes, muitas vezes, existem condições favoráveis para o estabelecimento de outras espécies invasoras, que normalmente não se estabeleceriam. As plantas invasoras, em seu processo de ocupação, aumentam sua área de ocorrência e dominam e eliminam a flora nativa por competição direta. Os animais são eliminados ou obrigados a sair do local à procura de alimentos, antes abundantes pela diversidade de espécies existentes. Assim, lentamente as invasões biológicas vão promovendo a substituição de comunidades com elevada diversidade por comunidades monoespecíficas, compostas por espécies invasoras, ou com diversidade reduzida (MMA, 2009a).

Outros efeitos resultantes da ocorrência de plantas invasoras podem passar pela alteração de ciclos ecológicos, como regime de fogo; quantidade de água disponível; alteração da composição e disponibilidade de nutrientes; remoção ou introdução de elementos nas cadeias alimentares; alteração dos processos geomorfológicos; e mesmo pela extinção de espécies (MMA, 2009a).

\section{- Custos Econômicos}

Espécies exóticas invasoras provocam muitos impactos negativos sobre os interesses econômicos, sejam eles locais, nacionais ou globais. Diminuem o rendimento de plantações, aumentam os custos de manejo e reduzem o suprimento de água ao degradarem ecossistemas e reservas de água doce (GISP, 2005).

Alguns estudos mostram esses custos:

- O Programa Global de Espécies Invasoras não tem uma estimativa do custo global agregado das invasões biológicas, mas um estudo conduzido pelos Estados Unidos avalia em 137 bilhões de dólares só nos Estados Unidos o custo anual associado a uma gama de espécies exóticas invasoras; 


\section{Then

- Um ácaro, praga que afeta abelhas melíferas, invadiu recentemente a Nova Zelândia e estima-se que acarretará um prejuízo econômico entre 260 e 600 milhões de dólares, forçando os produtores de mel a mudar a forma de manejo das colméias;

- $\quad$ Em 1992, um relatório da Weed Science Society of America estimava o custo total gerado por plantas exóticas invasoras entre 4,5 e 6,3 bilhões de dólares anuais nos Estados Unidos;

- $\quad$ No Reino Florístico da região do Cabo da Boa Esperança, na África do Sul, o estabelecimento de espécies invasoras arbóreas provocou diminuição do suprimento de água para as comunidades próximas, aumento do risco de incêndios e ameaças à biodiversidade nativa, justificando gastos governamentais de 40 milhões de dólares anuais com o controle manual e químico.

Dados publicados pelo MMA, 2009a mostra que, em estudos realizados nos Estados Unidos da América, Reino Unido, Austrália, Índia, África do Sul e Brasil, concluiuse que os custos decorrentes da presença de espécies exóticas invasoras nas culturas agrícolas, em pastagens e nas áreas de florestas atingem cifras anuais da ordem de US\$ 250 bilhões. Adicionalmente, os custos ambientais nesses mesmos países chegam a US\$ 100 bilhões anuais. Uma projeção mundial dessas cifras indica que as perdas globais anuais decorrentes do impacto dessas espécies ultrapassa US\$1,4 trilhões, aproximadamente 5\% do PIB mundial.

Considerando esses valores, estima-se que no Brasil esse custo pode ultrapassar os US\$ 100 bilhões anuais. Esse montante pode ainda sofrer aumento significativo, especialmente, se incluirmos os custos relacionados às espécies que afetam a saúde humana.

\section{- Custos à Saúde Humana}

Grandes obras, tais como represas projetos de irrigação, recuperação de terras, construção de estradas e programas de reassentamento têm contribuído para a invasão de doenças como a malária, o dengue, a esquistossomose e a tripanossomíase (GIPS, 2005). 
Gips 2005, ainda desperta para a gravidade da substituição de florestas:

Em regiões tropicais, a derrubada de florestas para aumento das terras agriculturáveis tem facilitado a transmissão mais abrangente de vírus propagadores de febres hemorrágicas que até então circulavam de forma benigna em hospedeiros selvagens. Exemplos incluem a febre hemorrágica argentina e os vírus Guaranito, Machupo e Basia. Algumas rotas de dispersão de invasões biológicas são complicadas. Por exemplo, no Egito, a prevalência de elefantíase ao sul do delta do Nilo aumentou vinte vezes desde a construção do reservatório de Aswan, na década de 1960. Este aumento deveu-se principalmente ao aumento de locais para procriação do mosquito transmissor, decorrente da elevação do lençol freático causada pela extensão da irrigação. O problema tem se agravado com a resistência aos pesticidas desenvolvida pelos mosquitos, decorrente do uso intenso de pesticidas na agricultura, e com fluxo contínuo dos trabalhadores rurais entre o campo e a cidade. Deste modo, espécies invasoras, variações nas precipitações pluviais anuais, temperatura, densidade populacional humana, mobilidade das populações e uso de pesticidas são todos fatores contributivos, que combinados geram um dos mais profundos desafios associados às espécies invasoras: a ameaça à saúde humana. (GIPS, 2005).

\section{O CONTROLE DE ESPÉCIES EXÓTICAS INVASORAS EM UNIDADES DE CONSERVAÇÃO}

A legislação brasileira em suas diversas esferas: Nacional, Estadual e Municipal encontra-se bem amparada sobre o controle de espécies exóticas invasoras nas Unidades de Conservação.

A Lei № 9.985 de 18 de julho de 2000, institui o Sistema Nacional de Unidades de Conservação da Natureza (SNUC), a qual regulamenta e rege o conjunto de Unidades de Conservação (UC) no Brasil.

Segundo o Artigo 31, do SNUC designa limitações à introdução de espécies exóticas em UCs:

Art. 31. É proibida a introdução nas unidades de conservação de espécies não autóctones.

$\S 10$ Excetuam-se do disposto neste artigo as Áreas de Proteção Ambiental, as Florestas Nacionais, as Reservas Extrativistas e as Reservas de Desenvolvimento Sustentável, bem como os animais e plantas necessários à administração e às atividades das demais categorias de unidades de conservação, de acordo com o que se dispuser em regulamento e no Plano de Manejo da unidade (BRASIL, 2000, p. 21). 
Observa-se que o Parágrafo destacado autoriza o uso de animais domésticos e/ou domesticados, como os animais de montaria, em Unidades de Conservação de Proteção Integral desde que haja plano de manejo explicitando os usos e restrições de cada atividade proposta e que as mesmas estejam sob exigências impostas pelo $\S 1^{\circ}$ do Art. 31 (ANDRADE, 2009).

O objetivo da criação de Unidade de Conservação é a manutenção da biodiversidade, sendo após a criação um desafio fazer com que se cumpra seu papel. A invasão por espécies exóticas é considerada a primeira causa de perda de biodiversidade em Unidades de Conservação (ZILLER; ZALBA, 2007), tornando-se necessário a busca de soluções para tal problema.

A Estratégia Nacional sobre Espécies Exóticas Invasoras (Resolução Conabio no 5/09) reconhece e enfatiza a necessidade de ações de erradicação, controle e monitoramento de espécies exóticas invasoras nas UCs.

Em Pernambuco, por meio do Sistema Estadual de Unidades de Conservação (SEUC-PE, Lei Estadual no 13.787/09), é proibida a introdução de espécies exóticas em Unidades de Conservação de proteção integral (art. 37), e é estabelecido que sejam tomadas medidas que desestimulem a introdução dessas espécies nas unidades de uso sustentável (art. 38).

Nas regiões Sul e Sudeste, respectivamente, os estados do Paraná e do Espírito Santo determinaram legalmente que devem ser elaborados planos de controle e erradicação das espécies exóticas invasoras nas Unidades de Conservação estaduais (Portaria IAP nº 192/05 e Instrução Normativa nº 3/07).

A visão necessária à solução de problemas com espécies exóticas invasoras envolve medidas de prevenção, controle, manejo e erradicação, analisadas caso a caso, de acordo com cada situação e com cada espécie. No caso de Unidades de Conservação, é crucial envolver ao menos a zona de amortecimento no combate a problemas de invasão e, em caso de espécies de interesse econômico, implementar regulamentação para uso ou restrição ao uso dessas espécies, sob o princípio poluidorpagador: quem polui precisa limpar, ou ao menos pagar a conta, desde que o Estado possa executar a ação (ZILLER; DEBERT, 2013). 


\section{ESTRATÉGIA PARA CONTROLE DE ESPÉCIES EXÓTICAS INVASORAS}

Ziller; Zalba 2007 cita alguns exemplos de ações a serem realizadas no intuito de servir como orientação para que diversos grupos possam contribuir para evitar e resolver problemas relacionados a espécies exóticas invasoras. Essas ações estão esquematizadas no Quadro 1.

Quadro 1: Ações para o manejo de espécies exóticas

\begin{tabular}{|c|c|}
\hline \multirow{4}{*}{ Com relação ao cultivo } & $\begin{array}{l}\text { Não cultivar ou comercializar plantas ornamentais exóticas } \\
\text { invasoras, especialmente se a dispersão de sementes é feita por } \\
\text { aves ou outros animais e se o uso se dará no meio rural ou em } \\
\text { áreas próximas de ambientes naturais; }\end{array}$ \\
\hline & $\begin{array}{l}\text { Não utilizar espécies exóticas invasoras em projetos de } \\
\text { paisagismo; }\end{array}$ \\
\hline & $\begin{array}{l}\text { Incorporar práticas de prevenção à disseminação e rotinas de } \\
\text { controle ao manejo das espécies exóticas invasoras que sejam } \\
\text { cultivadas. Se a dispersão da espécie é feita por animais, devem } \\
\text { ser buscadas alternativas para utilizar outras espécies cuja } \\
\text { contenção seja mais viável; }\end{array}$ \\
\hline & $\begin{array}{l}\text { Não utilizar espécies exóticas em projetos de restauração } \\
\text { ambiental. }\end{array}$ \\
\hline \multirow{3}{*}{$\begin{array}{l}\text { Com relação à } \\
\text { capacitação e educação }\end{array}$} & $\begin{array}{l}\text { Incorporar o tema de invasão biológica às disciplinas escolares e } \\
\text { estimular os alunos a realizarem pesquisas sobre o tema, para } \\
\text { formar profissionais que no futuro possam trabalhar essa questão } \\
\text { com conhecimento científico } \\
\text { e com naturalidade; }\end{array}$ \\
\hline & $\begin{array}{l}\text { Ajudar a formar e capacitar pessoas que trabalhem com manejo } \\
\text { ambiental e áreas afins; }\end{array}$ \\
\hline & $\begin{array}{l}\text { Ser um multiplicador e distribuir de informações sobre espécies } \\
\text { exóticas invasoras. }\end{array}$ \\
\hline \multirow{2}{*}{$\begin{array}{c}\text { Com relação a projetos } \\
\text { de introdução de novas } \\
\text { espécies }\end{array}$} & $\begin{array}{l}\text { Antes de apoiar um projeto de introdução de uma nova espécie no } \\
\text { país ou numa região em particular, avaliar se existem espécies } \\
\text { nativas ou exóticas não invasoras já introduzidas que sejam } \\
\text { apropriadas para executar a função desejada; }\end{array}$ \\
\hline & $\begin{array}{l}\text { Em projetos de introdução, deve-se promover a avaliação } \\
\text { completa de custos, de mercado e de benefícios previstos, } \\
\text { incluindo aspectos econômicos, ambientais, sociais e culturais. } \\
\text { Precisa-se avaliar com responsabilidade quem vai receber os } \\
\text { benefícios e quem poderá sofrer os impactos e pagar os custos } \\
\text { decorrentes de um processo de invasão pela espécie em foco; }\end{array}$ \\
\hline
\end{tabular}




\begin{tabular}{|c|c|}
\hline & $\begin{array}{l}\text { Especialmente no caso de criadouros e de projetos de piscicultura } \\
\text { que utilizam espécies exóticas, precisam ser desenvolvidos planos } \\
\text { de prevenção para evitar evasões e de contingência para o caso } \\
\text { dessas ocorrerem. É preciso ter consciência de que as estruturas } \\
\text { em geral são precárias para conter evasões ao cultivo e devem ser } \\
\text { previstas medidas de contenção e de controle. Deve ser avaliada a } \\
\text { opção de trabalhar com espécies nativas. Não devem ser } \\
\text { aprovados projetos de introdução de peixes exóticos e outras } \\
\text { espécies aquáticas, pois o potencial de invasão é imenso e, uma } \\
\text { vez que aconteça a invasão, a erradicação é praticamente } \\
\text { impossível. }\end{array}$ \\
\hline $\begin{array}{l}\text { Com relação a animais } \\
\text { domésticos }\end{array}$ & $\begin{array}{l}\text { Não soltar animais de estimação na natureza. Muitos são exímios } \\
\text { caçadores e outros se estabelecem e ocupam o lugar de espécies } \\
\text { nativas. }\end{array}$ \\
\hline & $\begin{array}{l}\text { Apoiar projetos de pesquisa que busquem avaliar o potencial de } \\
\text { espécies nativas para produção, restauração e paisagismo; }\end{array}$ \\
\hline Com relação à pesquisa & $\begin{array}{l}\text { Como há extrema carência de informação sobre o tema para } \\
\text { condições brasileiras, devem ser feitas pesquisas aplicadas para } \\
\text { ajudar a construir um arcabouço de boas práticas e soluções de } \\
\text { prevenção, erradicação, controle e manejo para espécies exóticas } \\
\text { invasoras, análises de rotas e vetores de dispersão e outros temas } \\
\text { de aplicação imediata. }\end{array}$ \\
\hline \multirow[b]{2}{*}{ Com relação ao direito } & $\begin{array}{l}\text { Aprender sobre o tema, para evitar que denúncias de controle de } \\
\text { espécies exóticas invasoras sejam julgadas como crime ambiental, } \\
\text { quando em verdade são ferramentas para a conservação da } \\
\text { diversidade biológica; }\end{array}$ \\
\hline & $\begin{array}{l}\text { Ajudar a criar jurisprudência e regulamentação para o tema, tais } \\
\text { como listas oficiais de espécies exóticas invasoras para referência } \\
\text { pública, regulamentação para uso de espécies de valor comercial e } \\
\text { análises de risco. }\end{array}$ \\
\hline
\end{tabular}

Adaptado de Ziller; Zalba, 2007.

\section{CONSIDERAÇÕES FINAIS}

Entende-se que são necessárias políticas, ferramentas e procedimentos nos níveis internacional, nacional e local para dar base à avaliação dos riscos associados à introdução de espécies exóticas invasoras e para estabelecer um equilíbrio entre atividades socioeconômicas legítimas e salvaguardas apropriados para a saúde de comunidades e de ecossistemas e o bem-estar da população humana.

O manejo efetivo de Unidades de Conservação precisa incluir um sistema permanente de prevenção e detecção precoce de espécies exóticas, assim como um bom diagnóstico de espécies já existente. 


\section{AGRADECIMENTOS}

Ao Núcleo de Estudos em Pesquisa e Planejamento Ambiental (NEPPA) da Universidade Federal de Lavras (UFLA) pelo apoio técnico-científico e ao CNPq, FAPEMIG e CAPES pelo apoio financeiro.

\section{REFERÊNCIAS}

ANDRADE, F. S. A. Contaminação biológica e o uso de animais de montaria no Parque Nacional da Serra do Cipó - MG. 2009. 131 p. Tese (Doutorado em Conservação de Ecossistemas Florestais ) - Universidade de São Paulo. Piracicaba, 2009.

ANDRADE, F. S. A.; MAGRO, T. C.; COUTO, H. T. Z. Presença e distribuição de espécies exóticas na zona de influência de duas trilhas no Parque Nacional da Serra do Cipó - MG. Scientia Forestalis. v. 40, n. 94, p. 157-165, 2012.

BIGGELI, P., 2000. The human dimensions of invasive woody plants. http://members.multimania.co.uk/WoodyplantEcology/docs/McNeely01-145.pdf Acessado em 20 de Fev. 2013.

BRASIL. MMA/SBF. Sistema Nacional de Unidades de Conservação da Natureza SNUC: Lei № 9.985, de 18 jul. 2000. Brasília, 28 p.

BRASIL. Portaria IAP n. 192, de 2 de Dezembro de 2005. Disponível em: http://celepar7.pr.gov.br/sia/atosnormativos/form_cons_ato1.asp?Codigo=1222 Acessado em: 20 de Fev. 2013.

BRASIL. Lei N. 13.787, de 08 de Junho de 2009. Institui o Sistema Estadual de Unidades de Conservação da Natureza - SEUC, no âmbito do Estado do Pernambuco. Publicado no DOE de 09/06/09, $22 \mathrm{p}$.

CONABIO. Resolução n. 5 de 21 de outubro de 2009. Dispõe sobre a Estratégia Nacional sobre espécies Exóticas Invasoras.

CDB. Convenção da diversidade biológica, 1992.

DECHOUM, M. S. Invasões biológicas e a oportunidade da Amazônia. Unidades de Conservação. http://uc.socioambiental.org/conserva\%C3\%A7\%C3\%A3o-dabiodiversidade/invas\%C3\%B5es-biol\%C3\%B3gicas-e-a-oportunidade-daamaz\%C3\%B4nia - Acessado em 24 de Fev. 2013.

DECHOUN, M. S. Espécies exóticas invasoras: o contexto internacional e a construção de políticas públicas e de estratégias nacionais. Caderno Mata Ciliar, São Paulo, n. 3, 2010. 
GISP - Programa Global de Espécies Invasoras. América do Sul invadida. A crescente ameaça das espécies exóticas invasoras. 80p, 2005.

GOMES, E. R. S. Espécies exóticas invasoras em unidades de conservação do Estado do Rio de Janeiro - Estudo de população de jaqueiras (Artocarpus heterophyllus L.) no Parque Natural Municipal do Mendanha. 2007. 96 p. Dissertação (Mestrado em Ciências Ambientais e Florestais) - Universidade Federal Rural do Rio de Janeiro. Seropédica. 2007.

LEÃO, T. C. C.; ALMEIDA, W. R.; DECHOUM, M. S.; ZLLER, S. R. Espécies Exóticas Invasoras no Nordeste do Brasil: Contextualização, Manejo e Políticas Públicas. Centro de Pesquisas Ambientais do Nordeste e Instituto Hórus de Desenvolvimento e Conservação Ambiental - Recife, PE. 99 p., 2011.

LEUNG, Y.F.; MARION, J.F. Recreation impacts and management in wilderness: a state of knowledge review. Fort Collins: USDA, Forest Service, Rock Mountain Research Station, 2000. 15p.

MACK, R.N.; Simberloff, D.; Lonsdale, W.M.; Evans, H.; Clout, M. e Bazzaz, F.A., 2000. Biotic Invasions: causes, epidemiology, global consequences and control. Issues in Ecolog.y n.5.

MMA - Ministério do Meio Ambiente, Disponível em:

http://www.mma.gov.br/biodiversidade/biosseguranca/especies-exoticas-

invasoras/estrategia-nacional- Acessado em 20 de Fev. de 2013.

MMA - Ministério do Meio Ambiente, Disponível em:

http://www.mma.gov.br/estruturas/174/_arquivos/anexo_resoluoconabio05_estrategia_nac ional_espcies_invasoras_anexo_resoluoconabio05_174.pdf - Acessado em 20 de Fev. de 2013.

MMA - Ministério do Meio Ambiente, Disponível em:

http://www.mma.gov.br/biodiversidade/biosseguranca/especies-exoticas-invasoras Acessado em 20 de Fev. de 2013.

PEREIRA, D. G. Densidade, genética e saúde populacional como ferramentas para propor um plano de controle e erradicação de invasão biológica: o caso de Callithris aurita (primates) no Parque Nacional da Serra dos Órgãos. 2010.161 p. Tese (Doutorado em Conservação do Meio Ambiente) - Universidade do Estado do Rio de Janeiro. Rio de Janeiro. 2010.

PICKERING, C.M.; HILL, W. Impacts of recreation and tourism on plants in protected areas in Australia. Canberra: Sustainable Tourism Cooperative Research Centre, 2007. 30p. 
ZILLER, S. R. Plantas exóticas invasoras: a ameaça da contaminação biológica. Ciência Hoje, p. 1-3, 2001.

ZILLER S.R. ZENNI R.D. \& NETO J.G. Invasões biológicas: Introdução, Impactos e espécies exóticas invasoras no Brasil. In: Princípios e Rudimentos do Controle Biológico de Plantas - Coletânea. Curitiba. Laboratório Neotropical de Controle Biológico de plantas. UFPR. 2004.

ZILLER, S. R.; ZALBA, S. Propostas de ação para prevenção e controle de espécies exóticas invasoras. Natureza \& Conservação, vol. 5, n. 2, p. 8-15, 2007.

ZILLER, R. S.; DEBERDT, A. J. Espécies exóticas invasoras em Unidades de Conservação. Disponível em: http://www.bolsadereciclaveis-

rs.com.br/bolsa/includes/pdf.php?arquivo=especies\%20exoticas\%20invasoras\%20em\%20 unidades\%20de\%20conservacao.pdf. Acessado em: 20 de Fev. 2013. 